NASA Technical Memorandum 106368

\title{
Probabilistic Assessment of Composite Structures
}

Michael C. Shiao and Galib H. Abumeri

Sverdrup Technology, Inc.

Lewis Research Center Group

Brook Park, Ohio

and

Christos C. Chamis

National Aeronautics and Space Administration

Lewis Research Center

Cleveland, Ohio

Prepared for the

34th Structures, Structural Dynamics and Materials Conference cosponsored by the AIAA, ASME, ASCE, AHS, and ASC La Jolla, California, April 19-23, 1993 


\title{
PROBABILISTIC ASSESSMENT OF COMPOSITE STRUCTURES
}

\author{
Michael C. Shiao and Galib H. Abumeri \\ Sverdrup Technology, Inc. \\ Lewis Research Center Group \\ Brook Park, Ohio 44142
}

and

Christos C. Chamis

National Aeronautics and Space Administration

Lewis Research Center

Cleveland, Ohio 44135

\section{SUMMARY}

A general computational simulation methodology for an integrated probabilistic assessment of composite structures is discussed and demonstrated using aircraft fuselage (stiffened composite cylindrical shell) structures with rectangular cutouts. The computational simulation was performed for the probabilistic assessment of the structural behavior including buckling loads, vibration frequencies, global displacements, and local stresses. The scatter in the structural response is simulated based on the inherent uncertainties in the primitive (independent random) variables at the fiber-matrix constituent, ply, laminate, and structural scales that describe the composite structures. The effect of uncertainties due to fabrication process variables such as fiber volume ratio, void volume ratio, ply orientation, and ply thickness is also included. The methodology has been embedded in the computer code IPACS (Integrated Probabilistic Assessment of Composite Structures). In addition to the simulated scatter, the IPACS code also calculates the sensitivity of the composite structural behavior to all the primitive variables that influence the structural behavior. This information is useful for assessing reliability and providing guidance for improvement. The results from the probabilistic assessment for the composite structure with rectangular cutouts indicate that (1) the uncertainty in the longitudinal ply stress is mainly caused by the uncertainty in the laminate thickness, and (2) the large overlap of the scatter in the first four buckling loads implies that the buckling mode shape for a specific buckling load can be either of the four modes.

\section{INTRODUCTION}

The technology of advanced fiber composites has progressed to the point that these composites are prime contenders for various aerospace applications. Their outstanding mechanical properties are very attractive to the aerospace industry, especially the ratio of high-strength/stiffness to density. They also possess excellent fatigue strength and the ability to resist corrosion and impact. However, the material properties of composites depend on a variety of primitive variables that are statistical in nature: fiber and matrix material properties at the constituent scale and fabrication variables at the ply scale (e.g., fiber volume ratio, void volume ratio, ply orientation, and ply thickness). Additionally, the service environments that these structures must endure are also random. Because the material properties of a typical composite cannot be adequately quantified deterministically, the behavior of composite structures exhibits considerable scatter from the mean value. Traditional approaches rely heavily on safety 
factors to account for the scatter in the materials and/or structural responses. These approaches usually result in an overly conservative design. In addition, they provide no indication of structural reliability. Innovative probabilistic approaches are needed to properly assess the composite structural response under uncertain service environments.

The NASA Lewis Research Center has been developing probabilistic composite mechanics and probabilistic composite structural analyses to quantify the scatter observed in composite properties and structural responses, respectively. The scatter in the observed materials and/or structural response has been related to the corresponding uncertainties in the governing physical parameters (i.e., the primitive variables including constituent material properties, fabrication process variables, structural component geometry, and other variables which contribute to the composite behavior and/or structural response). The probabilistic composite mechanics and the probabilistic composite structural analysis methodologies have been integrated in a single code, IPACS (Integrated Probabilistic Assessment of Composite Structures, ref. 1).

The objectives of this report are to (1) describe the methodology and the capabilities of the IPACS code and (2) demonstrate its effectiveness for an aircraft fuselage structure (stiffened composite cylindrical shell) with rectangular cutouts.

\section{SYMBOLS}

$\mathrm{E}_{\mathrm{f} 11}$ fiber modulus in longitudinal direction

$\mathrm{E}_{\mathrm{f} 22} \quad$ fiber modulus in transverse direction

$\mathrm{E}_{\mathrm{m}} \quad$ matrix elastic modulus

$\mathrm{F}_{\mathrm{x}} \quad$ axial force, kip

$\mathrm{F}_{\mathrm{y}} \quad$ lateral force, kip

$\mathrm{G}_{\mathrm{f} 12}$ in-plane fiber shear modulus

$\mathrm{G}_{\mathrm{f} 23}$ out-of-plane fiber shear modulus

$\mathrm{G}_{\mathrm{m}} \quad$ matrix shear modulus

$\mathrm{K}$ translational spring constant, kip/in.

$\mathrm{K}_{\theta} \quad$ torsional spring constant, kip/rad

$\mathrm{M}_{\mathrm{xx}} \quad$ torsional moment, kip- $\mathrm{ft}$

$t_{p s k} \quad$ ply thickness of shell skin, in.

$t_{\text {pst }}$ ply thickness of frames, in.

$\theta_{\mathrm{p}} \quad$ ply misalignment, deg

$v_{f 12}$ in-plane fiber Poisson's ratio

$v_{\mathrm{f} 23}$ out-of-plane fiber Poisson's ratio

$v_{\mathrm{m}} \quad$ matrix Poisson's ratio 


\section{FUNDAMENTAL CONSIDERATIONS}

The fundamental concepts implemented in the probabilistic composite assessment described herein are (1) the scatter in the composite structures for the probabilistic assessment should be traced to the lowest scale of influence; (2) the identified uncertain variables are called primitive variables and should include those resulting from the composite fabrication; (3) the scatter in all the primitive variables (described as the composite material and/or structure, supports, and service loads and/or environments) can be represented by specified probabilistic distributions; (4) these variables can be used in conjunction with composite mechanics and finite-element structural analysis to predict composite material and/or structural behavior, and (5) the simulation can be repeated many times to obtain sufficient information to develop the distribution of the ply property, composite property, and/or structural response.

The primitive variables at the various composite scales are (1) fiber and matrix material property at the fiber-matrix constituent scale; (2) fiber volume ratio, void volume ratio, ply orientation, and ply thickness at the ply scale; (3) geometry, supports, loads, and service environments at the structural scale. The methodology developed for the assessment of composite structures has been embedded in the computer code IPACS. Figure 1 shows the physics which forms the basis of the IPACS code.

\section{INTEGRATED PROBABILISTIC ASSESSMENT OF COMPOSITE STRUCTURES (IPACS)}

IPACS integrates several NASA in-house computer codes as shown in figure 2. COBSTRAN (COmposite Blade STRuctural ANalyzer, ref. 2) is a dedicated finite-element model generator for composite structures. PICAN (Probabilistic Integrated Composite Analyzer, ref. 3), based on composite mechanics and probability theory, enables the computation of the perturbed and probabilistic composite material properties and/or structural responses at the constituent, ply, and laminate scales. NESSUS (Numerical Evaluation of Stochastic Structure, ref. 4), based on structural mechanics and probability theory, uses the results from PICAN to simulate the perturbed and probabilistic structural response at the global and laminate scales. PICAN and NESSUS share the FPI (fast probability integrator, ref. 5) module for the application of the fast probability integration algorithm to obtain the probability density functions of the materials behavior and structural response.

The probabilistic assessment of composite structures using IPACS starts with the identification of primitive variables at the micro- and macrocomposite scales including the fabrication process. These variables are selectively perturbed several times in order to create a data base for the determination of the relationships between the desired materials behavior and/or structural response and the primitive variables. The composite micromechanics is used to carry over the scatter in primitive variables to the ply and laminate scales (steps A and B in fig. 1). Laminate theory is then used to determine the scatter in the material behavior at the laminate scale (step C). This step leads to the perturbed resultant force/ moment-displacement/curvature relationships used in the structural analysis. Next, the finite-element analysis is performed to determine the perturbed structural responses corresponding to the selectively perturbed primitive variables (step D). This completes the description of the hierarchical composite material/structure synthesis shown on the left side of figure 1 . The multiscale progressive decomposition of the structural response to the laminate, ply, and fiber-matrix constituent scales is shown on the right side of figure 1 (steps $\mathrm{E}$ to $\mathrm{G}$ ). After the decomposition, the perturbed fiber, matrix, and ply stresses can be determined. An important feature of IPACS, depicted at the bottom of figure 1, is the 
nonlinear multifactor interaction model for computing the fiber-matrix constituent material properties, including the effects of the prevailing service environments.

Next, the fast probability integrator (FPI) is used to determine the functional relationship between the response and the primitive variables. The cumulative distribution function of the response is then calculated with the numerically determined functional relationship and the known probability density function of the primitive variables. The sensitivity factors of the primitive variables to each response's cumulative probability are also determined. This information is crucial for the reliability assessment. Specific applications of the IPACS computer code are described in reference 6 (design for cyclic loading), reference 7 (composite structural design), and references 8 and 9 (smart composite structures).

\section{DEMONSTRATION OF IPACS FOR AIRCRAFT STRUCTURES}

IPACS is demonstrated for probabilistic static, frequency, and buckling analyses of an aircraft structure (stiffened composite cylindrical shell) with several rectangular cutouts. The composite structure is composed of graphite fibers and epoxy matrix. It consists of 8 vertical stringers, 5 circumferential frames, and a cylindrical shell with 12 cutouts (shown in fig. 3). The diameter of the cylindrical shell is $20 \mathrm{ft}$ and its length is $50 \mathrm{ft}$. The shell is supported at one end by a set of translational and torsional springs and is unconstrained at the other end where random loads are applied as shown in figure 4. The modeling of supports using translational and torsional springs allows partially fixed boundary conditions to enable the simulation of real-life conditions. For instance, when the spring constant approaches infinity, a completely fixed support condition is simulated. If the spring constant is set to zero, a free support condition is represented. For spring constant values between infinity and zero, a partially fixed support condition is modeled, and the uncertainty in the support conditions can be represented by probability density functions of the spring constants. The composite configurations of the shell skin, stringers, and frames are $\left[ \pm 45 / 0_{2} / \pm 45 / 0_{2} / \pm 45 / 0 / 90\right]_{\mathrm{S}},\left[\mathrm{O}_{24}\right]$, and $\left[\mathrm{O}_{24}\right]$ respectively. The structure is modeled by 1256 nodes (six degrees of freedom per node) and 1196 four-noded shell elements.

The probabilistic assessment is carried out by identifying the primitive variables at the constituent, ply, and structural scales. Table I presents the probability information on the primitive variables related to the fiber-matrix constituent materials. Table II provides the same information for the primitive variables related to the fabrication process and loading/boundary conditions. These types of distributions for all the variables are assumed in this study. However, potential users should determine such statistical information from available data.

\section{RESULTS}

\section{Probabilistic Static Responses}

Scatter in the displacements and stresses is simulated on the basis of the uncertainties listed in tables I and II.

The probability density functions (PDF) of the displacements at locations A and B along the shell circumference at the free end are shown in figure 5. The mean displacements at locations A and B are given in table III. It is readily known that the mean displacements at the free end of the fuselage are 
increased by 11 to 19 percent with rectangular cutouts. The displacement corresponding to the 0.999 cumulative probability at location B was determined to be 2.57 in. This information can be used to assess the reliability with respect to the design allowable for the displacement clearance. For example, if the design reliability is set at 0.999 with the allowable displacement at 3 in., the failure probability will be less than 0.001 . However, if the allowable displacement is set at 2 in., the failure probability will be greater than 0.001 . The reliability requirement is therefore violated. The sensitivity factors, which rank the importance of random variables to the probability distribution of the displacement, are shown in figure 6. The result indicates that at a 0.999-probability level, the random force in the Ydirection contributes the most probability (sensitivity factor of 0.93 ), followed by laminate thickness, fiber moduli, and fiber volume ratio of the skin (sensitivity factors of $0.26,0.15,0.15$, respectively).

The PDF's of the stresses in the $+45^{\circ},-45^{\circ}$, and $0^{\circ}$ plies near the root between the cuts (location $\mathrm{C}$ in fig. 5), normalized with respect to the mean stress in the $0^{\circ}$ ply, are plotted in figure 7 . The maximum longitudinal stress occurs in the $0^{\circ}$ ply. The mean value of this maximum stress is increased by 7 percent with rectangular cutouts, as shown in table III. The stresses in the fiber direction in the $+45^{\circ}$ and $-45^{\circ}$ plies are 40 and 20 percent, respectively, of that of the $0^{\circ}$ ply. This result indicates that $0^{\circ}$ plies carry most external loads. The sensitivity factors for the longitudinal stress in the $0^{\circ}$ ply are shown in figure 8 . At a probability of 0.001 , the skin laminate thickness contributes the most probability to the ply stress (sensitivity factor of 0.84 ). The next highest contribution is made by the random forces in the axial and lateral directions (sensitivity factors of 0.37 and 0.34 ). The normalized longitudinal, transverse, and shear stresses in the $+45^{\circ},-45^{\circ}$, and $0^{\circ}$ plies (normalized by the mean longitudinal stress in each ply) are shown in figures 9 to 11 . The transverse and shear stresses are negligible in the $0^{\circ}$ ply. The transverse and shear stresses in $+45^{\circ}$ plies are also small (less than 20 percent of their respective longitudinal stresses).

\section{Probabilistic Buckling Loads}

The mean values of the buckling loads (in table IV) are decreased by 8 to 15 percent with rectangular cutouts. The probabilistic buckling loads of the first four modes are shown in figure 12. These four modes exhibit a mixed skin and stringer buckling behavior. Note the large overlap of the PDF for the buckling modes in figure 12 . This overlap implies that the buckling mode shape for a specific buckling load can be either of these four modes. The sensitivity factors for the first mode are plotted in figure 13. The first mode at a probability of 0.001 is influenced the most by the skin laminate thickness (sensitivity factor of 0.73 ), followed by the skin fiber volume ratio (sensitivity factor of 0.46 ), skin fiber modulus (sensitivity factor of 0.40), and stringer laminate thickness (sensitivity factor of 0.25 ). Note that the stringer fiber modulus has little contribution to the cumulative probability.

\section{Probabilistic Vibration Frequencies}

The mean values of the natural frequencies (in table V) are decreased by 1 to 5 percent with rectangular cutouts. This result indicates that the cutouts have less influence on the frequencies than on the buckling loads. The first four natural vibration frequencies are plotted in figure 14. It can be seen that the first and second frequencies are only slightly different. The third and fourth frequencies are also very close. The difference is the result of the unsymmetric cutouts. The first and second modes are mainly the torsional modes while the third and fourth are the mixed torsion and bending modes. 
The sensitivity factors for the first vibration frequency are shown in figure 15 . At 0.001 probability, the fiber modulus and fiber volume ratio of the skin and of the stringer make a significant contribution to the first vibration frequency (sensitivity factors range from 0.59 to 0.38 ). The stringer laminate thickness also has some effect on the first vibration frequency (sensitivity factor of 0.10 ) whereas the skin laminate thickness has almost no effect (sensitivity factor of 0.01).

\section{CONCLUDING REMARKS}

The computer code IPACS is a general and powerful code for the comprehensive probabilistic assessment of composite structures. The uncertainties are identified at the lowest possible levels, and proper composite and structural mechanics are used to quantify the scatter ranges of the uncertain structural responses. In addition, the code is computationally efficient through the use of the FPI (fast probability integrator) technique, instead of the Monte Carlo simulation, for the probabilistic calculations. The formal procedure embedded in IPACS integrates composite mechanics, finite-element methods, and probability theory for a comprehensive probabilistic analysis considering the uncertainties in all composite scales (constituent, ply, laminate, structural). A stiffened composite cylindrical shell with cutouts was used to demonstrate the effectiveness of the methodology. The displacements at the tip and the stress near the root were increased because of the cutouts. The buckling loads and natural frequencies were decreased for the same reason. The scatter range of the composite structural responses was adequately quantified. For the specific problem treated in the report, the uncertainty in the longitudinal stress was mainly caused by the uncertainty in the laminate thickness. Moreover, the large overlap of the scatter in the first four modes implied that the buckling mode shape for a specific buckling load could be either of these four modes. Also from the study, the sensitivity information can be used to select the most efficient approach to reduce the scatter of the structural responses and to satisfy the design requirements.

IPACS has more capability than described in this report. For example, for composite structures in a hygrothermal service environment, IPACS code can simulate the structural behavior and determine its fatigue life. The reliability of the structure against a specified design criterion can also be determined. Also, the adaptation of the intraply hybrid composite concept to smart composite structures enables the probabilistic assessment of smart structures, allowing various tradeoff studies to be performed to obtain the least-cost/maximum-benefit configuration.

\section{REFERENCES}

1. Chamis, C.C.; and Shiao, M.C.: IPACS-Integrated Probabilistic Assessment of Composite Structures: Code Development and Applications. Third NASA Advanced Composites Technology Conference, Vol. 1, Pt. 2, J.G. Davis, Jr. and H.L. Bohan, eds., NASA CP-3178-VOL-1-PT-2, 1993, pp. 987-999.

2. Aiello, R.A.: COmposite Blade STRuctural Analyzer (COBSTRAN) User's Manual. NASA TM-101461, 1989.

3. Liaw, D.G., et al.: Probabilistic Simulation of Multiscale Composite Behavior. NASA TM-106196, 1993. 
4. Probabilistic Structural Analysis for Select Space Propulsion System Structural Components. Annual Report. Southwest Research Institute, Rocketdyne, University of Arizona, Marc Analysis Corporation, Columbia University, NASA Contract NAS3-24389, 1986.

5. Wu, Y.T.: Demonstration of a New, Fast Probability Integration Method for Reliability Analysis. Advances in Aerospace Structural Analysis, O.H. Burnside and C.H. Parr, eds., ASME, New York, 1985, pp. 63-73.

6. Shiao, M.C.; and Murthy, P.L.N.: Design for Cyclic Loading Endurance of Composites. Proceedings of the 24th International SAMPE Technical Conference, T.S. Reinhart, et al., eds., Society for Advancement of Materials and Process Engineering, Covina, CA, 1992, pp. T241-T255.

7. Shiao, M.C.; and Singhal, S.N.: Probabilistic Assessment of Composite Structural Design. Proceedings of the 24th International SAMPE Technical Conference, T.S. Reinhart, et al., eds., Society for Advancement of Materials and Process Engineering, Covina, CA, 1992, pp. T461-T472.

8. Shiao, M.C.; and Chamis, C.C.: Probabilistic Assessment of Uncertain Adaptive Hybrid Composites. Third International Conference on Adaptive Structures, B.K. Wade, M. Natori, and E.J. Breitbach, eds., Technomic Pub. Co., 1993, pp. 458-472.

9. Chamis, C.C.; and Shiao, M.C.: Probabilistic Assessment of Smart Composite Structures. Advanced Materials: Performance Through Technology Insertion: the 38th International SAMPE Symposium, G.C. Janicki, V. Bailey, and T. Haulik, eds., Society for Advancement of Materials and Process Engineering, Covina, CA, 1993, pp. 1303-1312. 
TABLE I-STATISTICS OF MATERIAL PROPERTIES AT CONSTITUENT

LEVEL FOR SKIN

AND FRAMES

[Assumed distribution type, normal; assumed coefficient of variation, 0.05 .]

\begin{tabular}{|l|c|}
\hline \multicolumn{1}{|c|}{ Primitive parameter } & $\begin{array}{c}\text { Assumed } \\
\text { mean }\end{array}$ \\
\hline Fiber modulus direction, Mpsi & \\
Longitudinal, $\mathrm{E}_{\mathrm{f} 11}$ & 31.0 \\
Transverse, $\mathrm{E}_{\mathrm{f} 22}$ & 2.0 \\
Fiber shear modulus, Mpsi & 2.0 \\
In-plane, $\mathrm{G}_{\mathrm{f} 12}$ & 1.0 \\
Out-of-plane, $\mathrm{G}_{\mathrm{f} 23}$ & .2 \\
Fiber Poisson's ratio & .25 \\
In-plane, $\mathrm{v}_{\mathrm{f} 12}$ & \\
Out-of-plane, $\mathrm{v}_{\mathrm{f} 23}$ & .5 \\
Matrix & .185 \\
Elastic modulus, $\mathrm{E}_{\mathrm{m}}, \mathrm{Mpsi}$ & .35 \\
Shear modulus, $\mathrm{G}_{\mathrm{m}}, \mathrm{Mpsi}$ & \\
Poisson's ratio, $\mathrm{v}_{\mathrm{m}}$ & \\
\hline
\end{tabular}

TABLE II.-STATISTICS OF FABRICATION VARIABLES, RANDOM

LOADS, AND SPRING CONSTANTS

[Assumed distribution type, normal; assumed coefficient of variation, 0.05.]

\begin{tabular}{|l|c|}
\hline \multicolumn{1}{|c|}{ Primitive variable } & $\begin{array}{c}\text { Assumed } \\
\text { mean }\end{array}$ \\
\hline Volume ratio & \\
Fiber & 0.60 \\
Void & .02 \\
Ply & 0 \\
Orientation, $\theta_{\mathrm{p}}{ }^{\mathrm{a}}{ }^{\mathrm{deg}}$ & .005 \\
Thickness of shell skin, $\mathrm{t}_{\mathrm{psk}}$, in. & .020 \\
Thickness of frames, $\mathrm{t}_{\mathrm{pst}},{ }^{\mathrm{in} .}$ & 1200 \\
Force, kip & 120 \\
Axial, $\mathrm{F}_{\mathrm{x}}$ & 1200 \\
Lateral, $\mathrm{F}_{\mathrm{y}}$ & \\
Torsional moment, $\mathrm{M}_{\mathrm{xx}}, \mathrm{kip}^{\mathrm{ft}}$ & $20 \times 10^{6}$ \\
Spring constant & $30 \times 10^{4}$ \\
\hline Translational, $\mathrm{K}, \mathrm{kip} / \mathrm{in}$. & \\
Torsional, $\mathrm{K}_{\mathrm{\theta}}, \mathrm{kip} / \mathrm{rad}$ &
\end{tabular}

${ }^{\mathrm{a}}$ Assumed coefficient of variation, 1.00 (stdv).
TABLE III.-STIFFENED COMPOSITE SHELL

MEAN DISPLACEMENT AND STRESS

AT LOCATIONS A, B, AND $C^{a}$

[Locations shown in fig. 5.]

\begin{tabular}{|l|c|c|c|}
\hline \multirow{2}{*}{$\begin{array}{c}\text { Shell } \\
\text { structure }\end{array}$} & \multicolumn{2}{|c|}{$\begin{array}{c}\text { Displacement } \\
\text { location }\end{array}$} & $\begin{array}{c}\text { Longitudinal } \\
\text { stress in } \\
0^{\circ} \text { ply at } \\
\text { location C }\end{array}$ \\
\cline { 2 - 3 } & $\mathrm{A}$ & $\mathrm{B}$ & 1 \\
\hline $\begin{array}{l}\text { Without cutouts } \\
\text { With cutouts }\end{array}$ & 1 & 1 & 1.07 \\
\hline
\end{tabular}

${ }^{a}$ Normalized by respective value without cutouts.

TABLE IV.-MEAN BUCKLING LOADS OF STIFFENED COMPOSITE SHELL ${ }^{\mathrm{a}}$

\begin{tabular}{|l|c|c|c|c|}
\hline \multirow{2}{*}{\multicolumn{1}{c|}{$\begin{array}{c}\text { Shell } \\
\text { structure }\end{array}$}} & \multicolumn{4}{|c|}{ Buckling load } \\
\cline { 2 - 5 } & First & Second & Third & Fourth \\
\hline Without cutouts & 1 & 1 & 1 & 1 \\
With cutouts & 0.92 & 0.88 & 0.85 & 0.87 \\
\hline
\end{tabular}

${ }^{a}$ Normalized by respective buckling load for each mode without cutouts.

TABLE V.-MEAN NATURAL FREQUENCIES OF STIFF-

ENED COMPOSITE SHELL ${ }^{\mathrm{a}}$

\begin{tabular}{|l|c|c|c|c|}
\hline \multirow{2}{*}{\multicolumn{1}{c|}{$\begin{array}{c}\text { Shell } \\
\text { structure }\end{array}$}} & \multicolumn{4}{|c|}{ Frequency } \\
\cline { 2 - 5 } & First & Second & Third & Fourth \\
\hline Without cutouts & 1 & 1 & 1 & 1 \\
With cutouts & 0.98 & 0.99 & 0.95 & 0.98 \\
\hline
\end{tabular}

${ }^{a}$ Normalized by respective frequency for each mode without cutouts. 


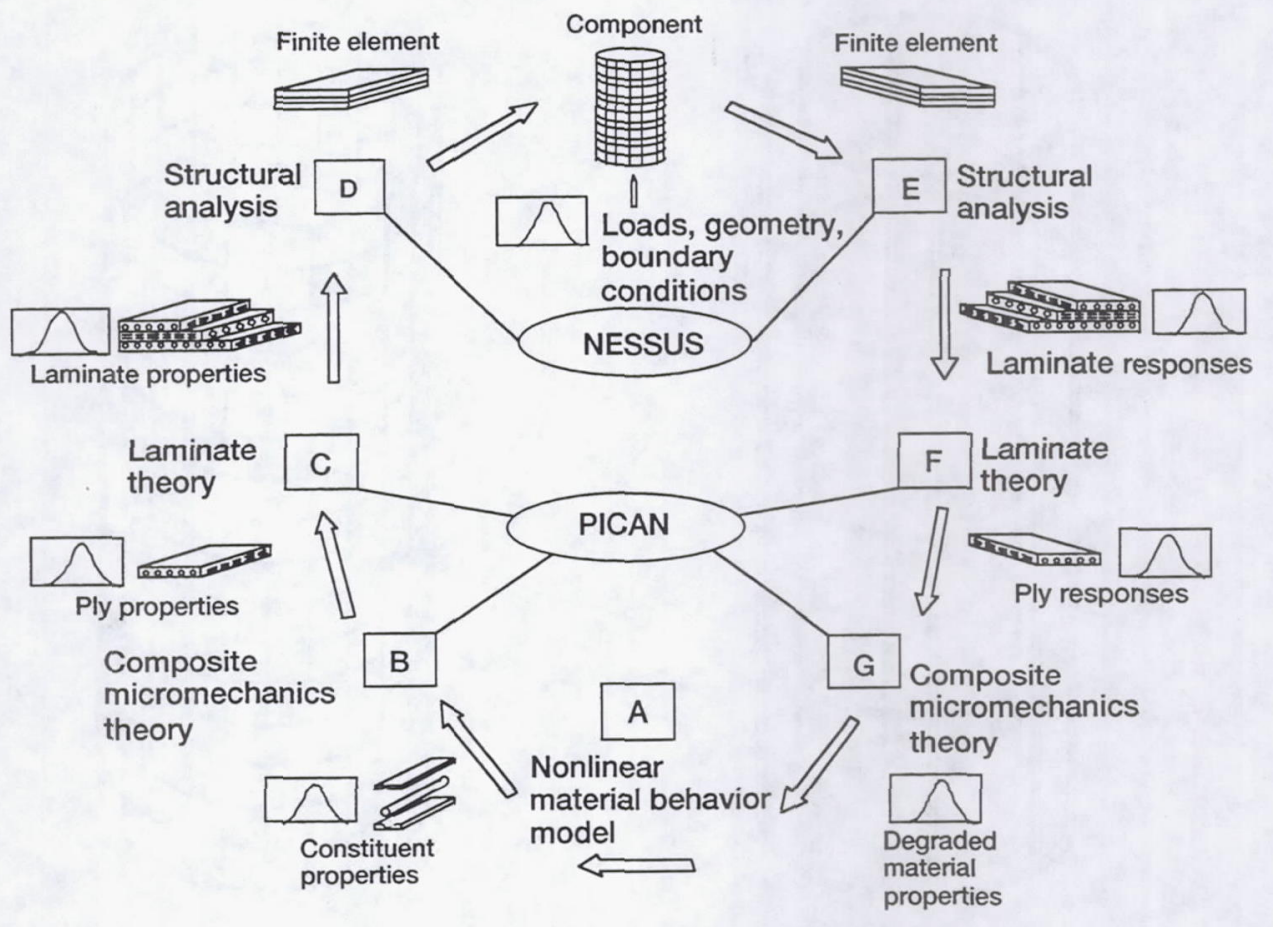

Figure 1.-Concept of probabilistic assessment of composite structures.

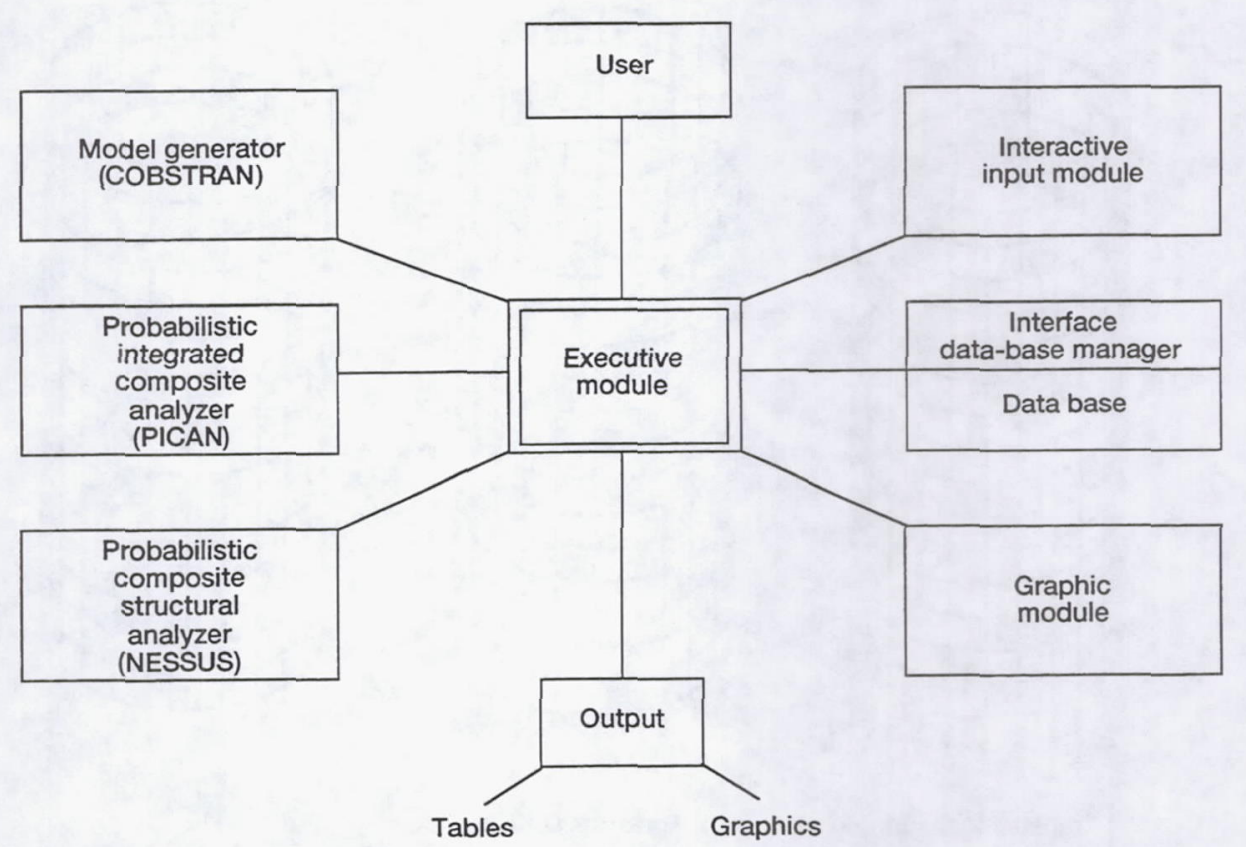

Figure 2.-Architecture of IPACS (Intergrated Probabilistic Assessment of Composite Structures) computer code. 


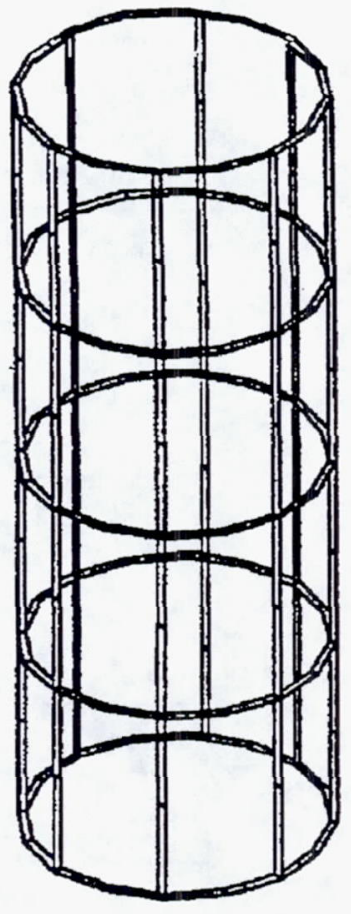

(a) Frames/stringers.

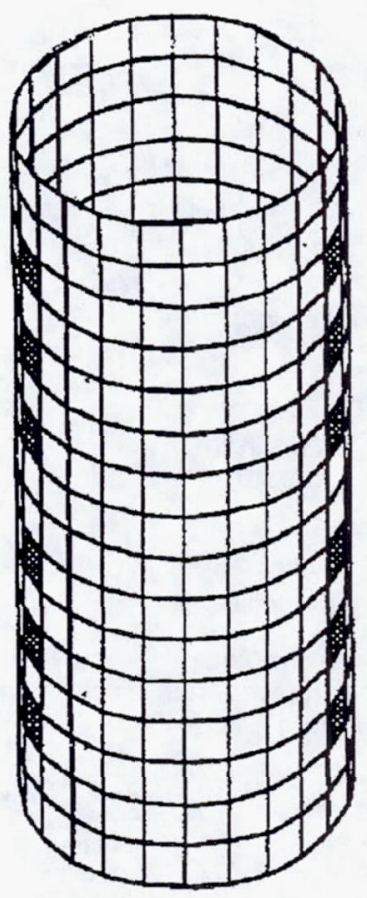

(b) Skin.

Figure 3.-Finite-element model of composite cylindrical shell.

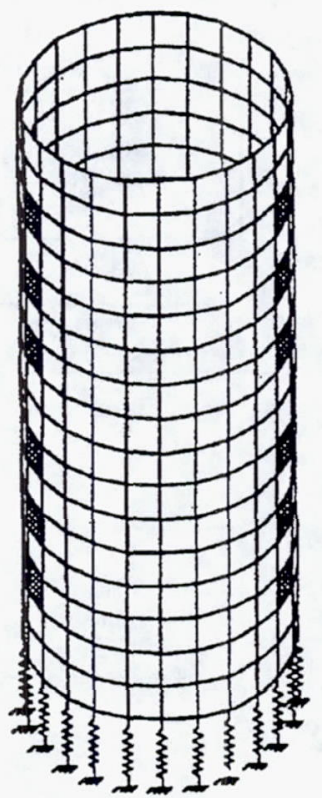

(a) Translational springs.

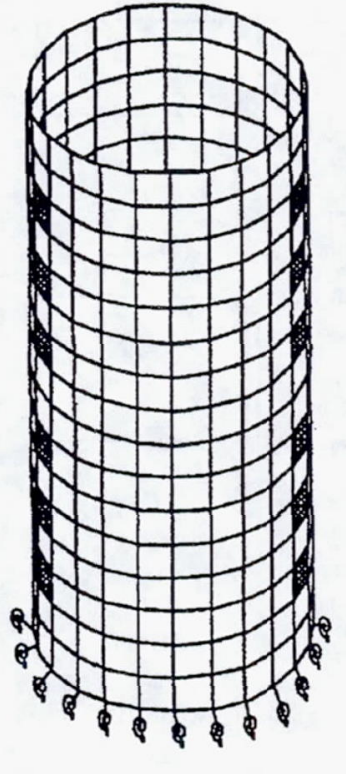

(b) Torsional springs.

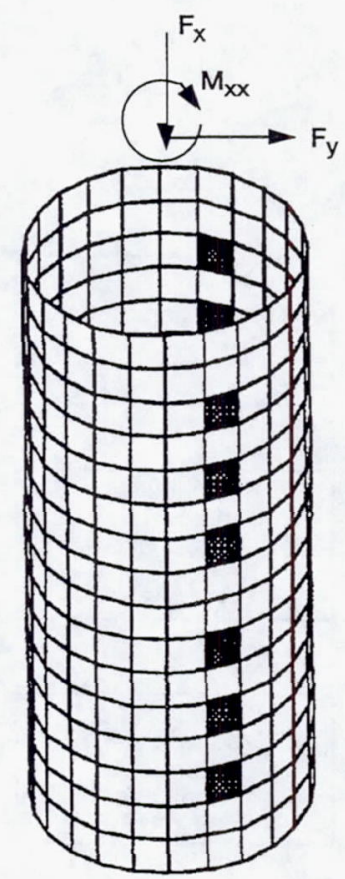

(c) Loading.

Figure 4.-Boundary and loading conditions of composite cylindrical shell. 

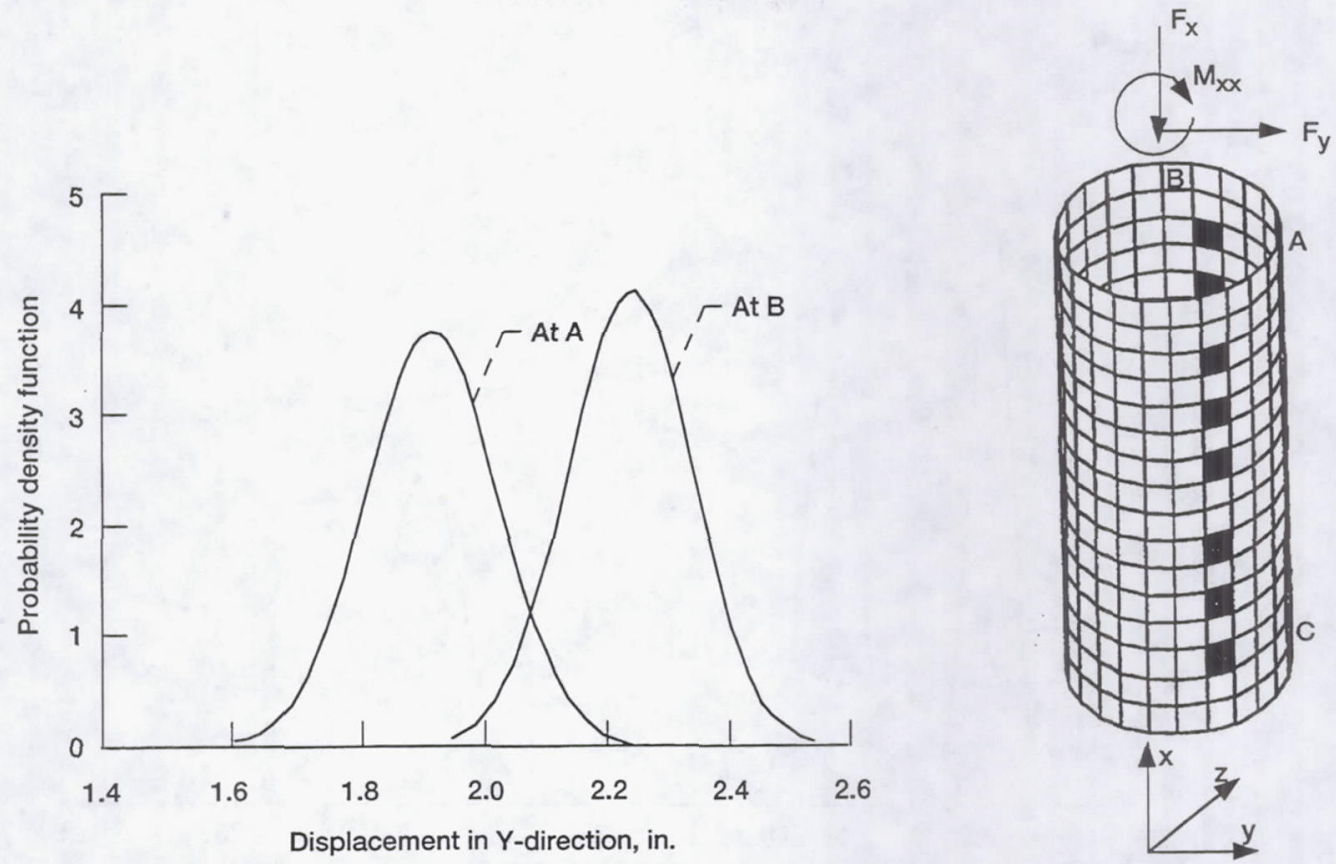

Figure 5.-Uncertainties - scatter range of displacement in Y-direction.

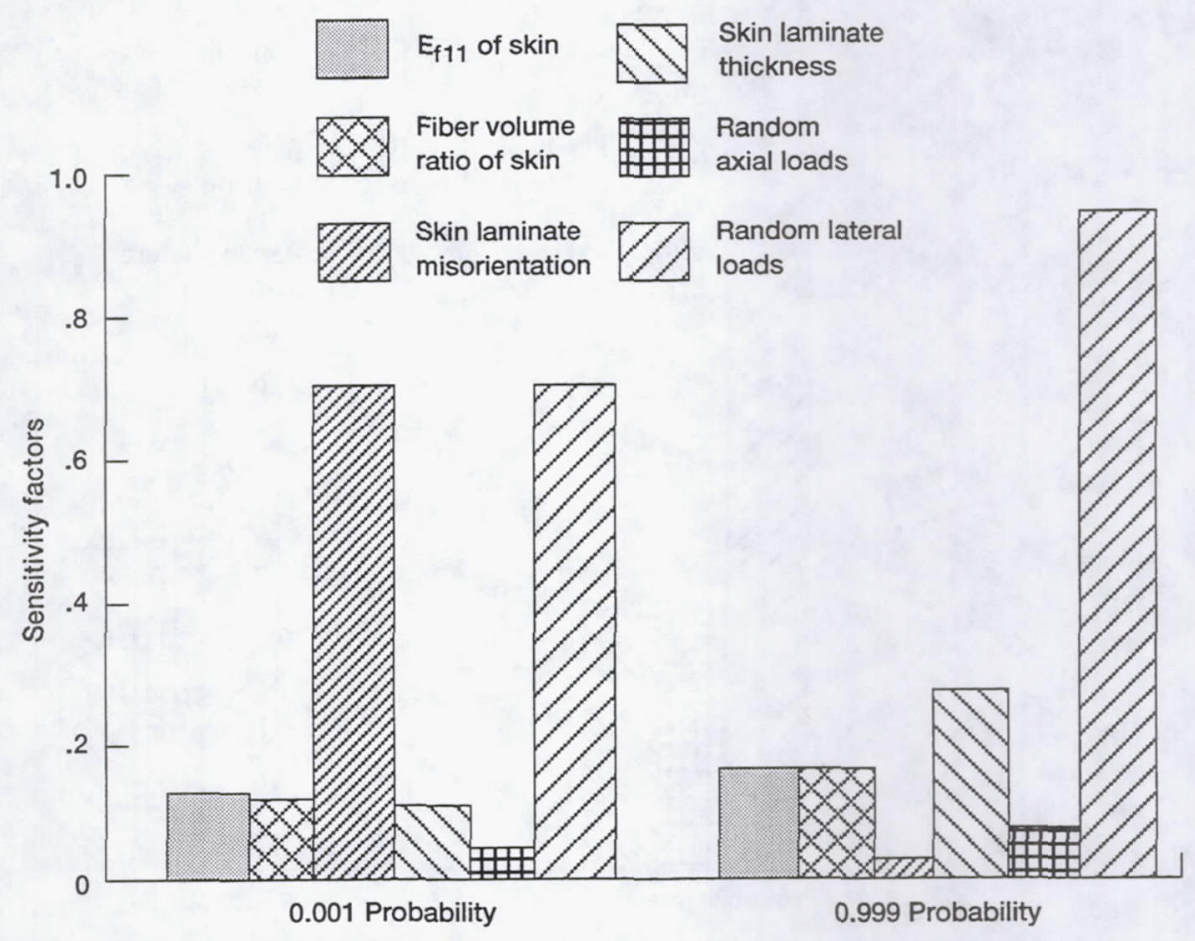

Figure 6.-Sensitivies of probabilistic displacement in Y-direction (at location B in fig. 5) to significant uncertain variables. 


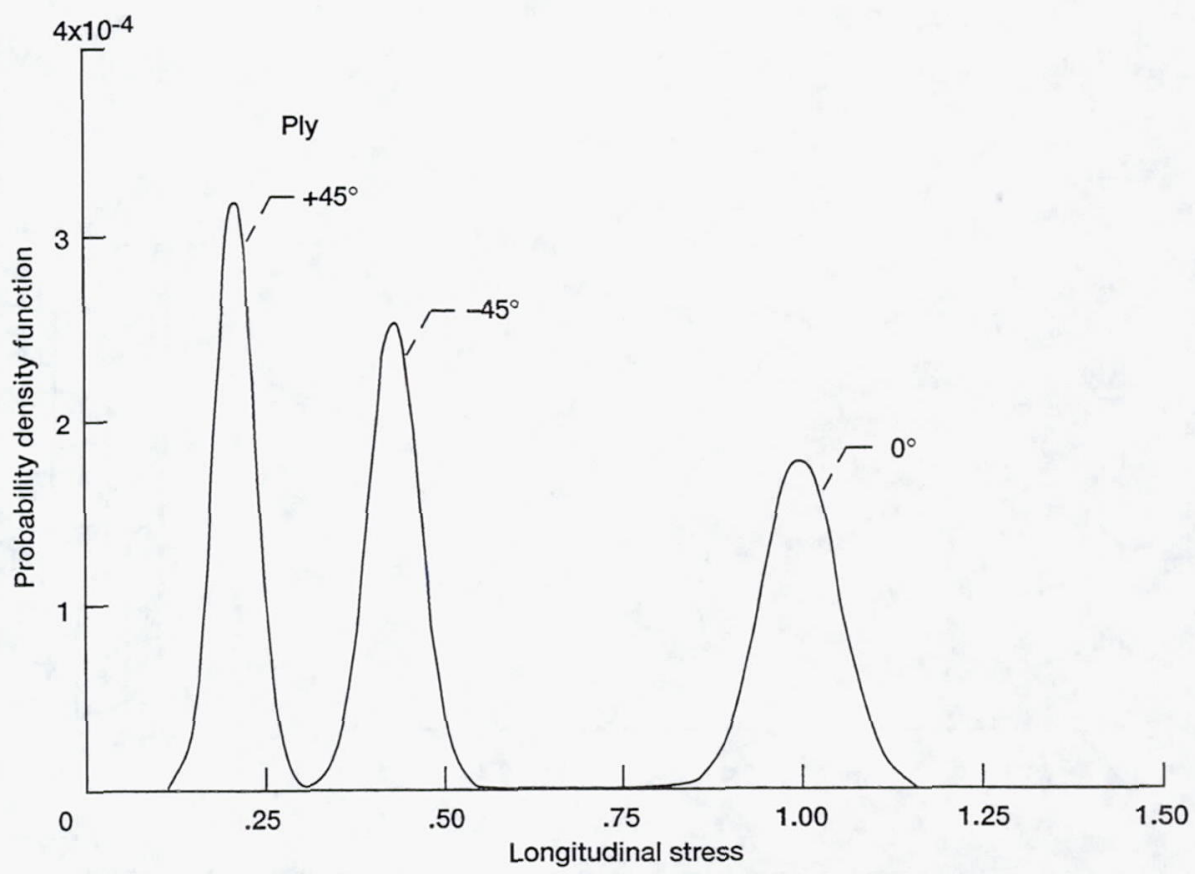

Figure 7.-Uncertainties - scatter range of normalized longitudinal stresses (at location $\mathrm{C}$ in fig. 5 ; normalized by mean stress in $0^{\circ}$ ply).

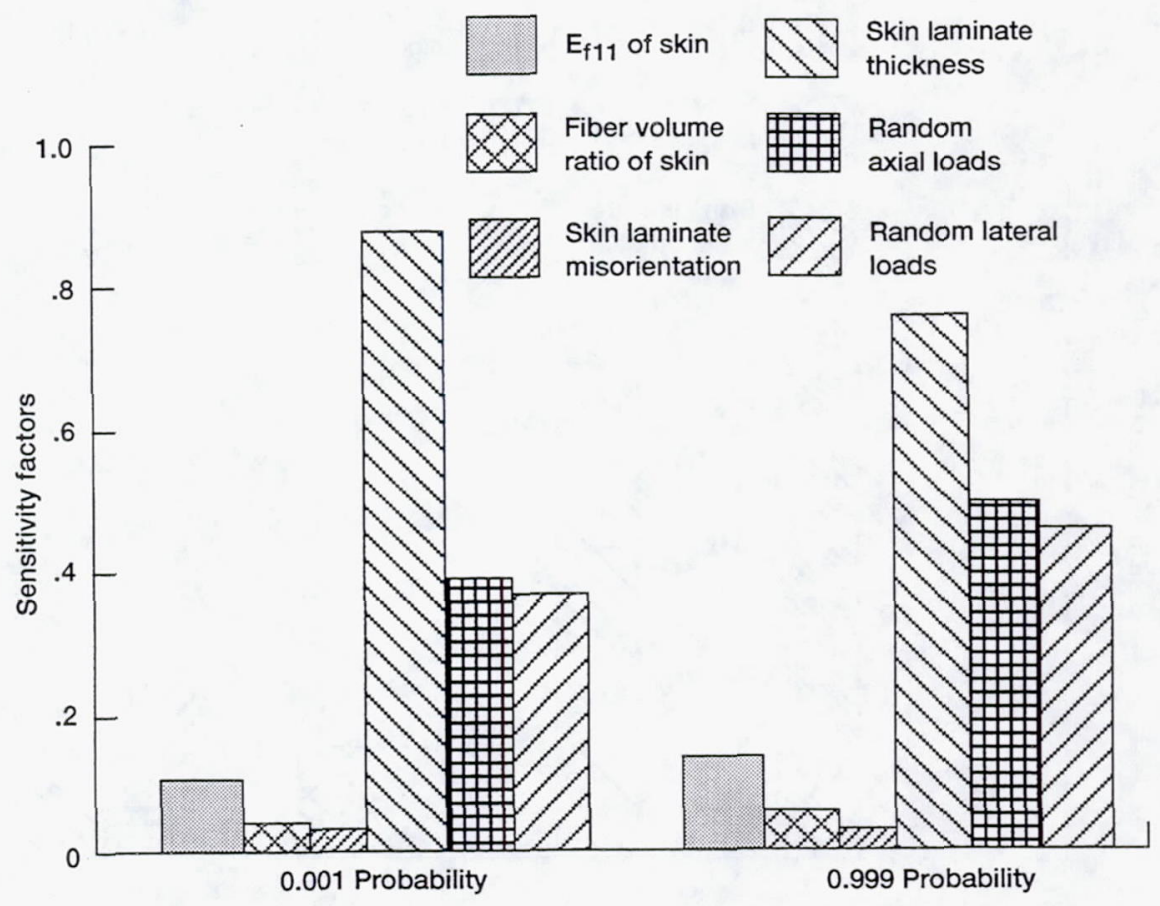

Figure 8.-Sensitivies of probabilistic $0^{\circ}$ ply longitudinal stress to significant uncertain variables. 


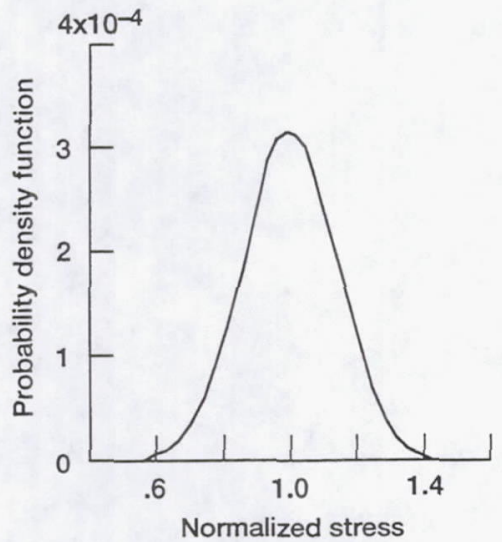

(a) Longitudinal.

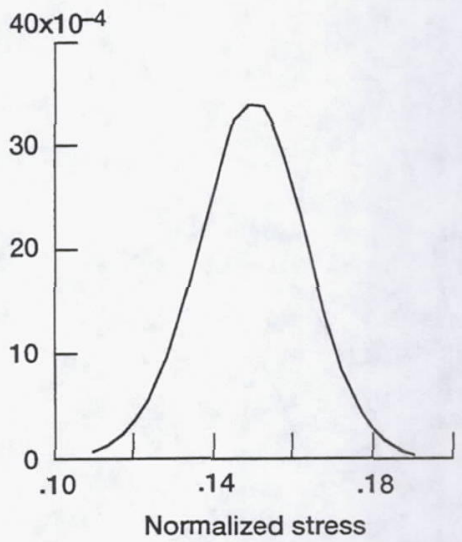

(b) Transverse.

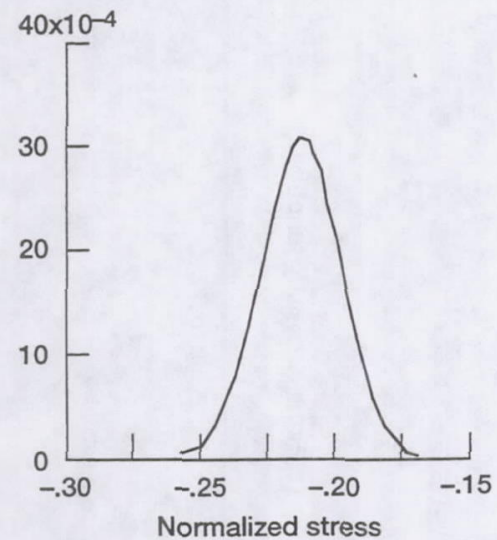

(c) Shear.

Figure 9.-Uncertainties - scatter range of normalized stresses in $+45^{\circ}$ ply (normalized by mean longitudinal stress).

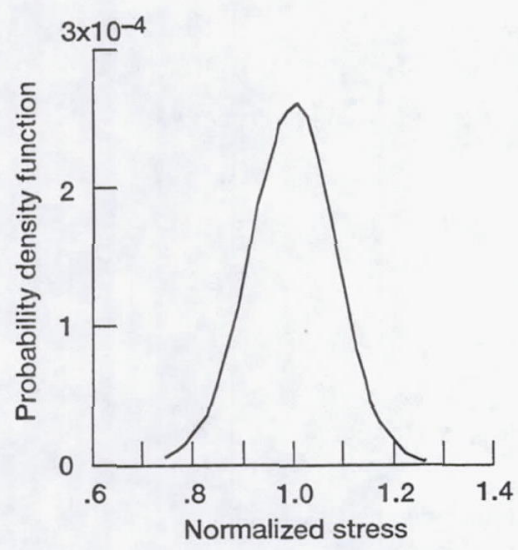

(a) Longitudinal.

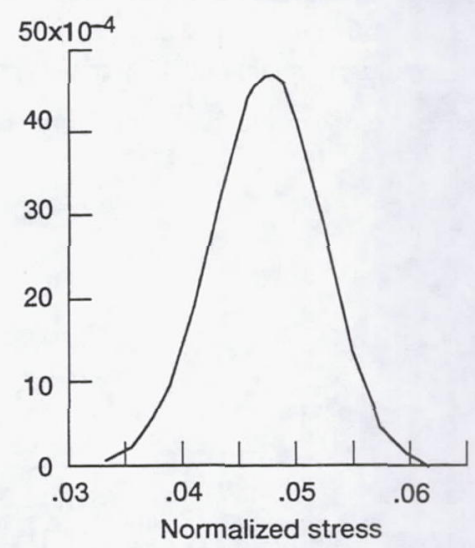

(b) Transverse.

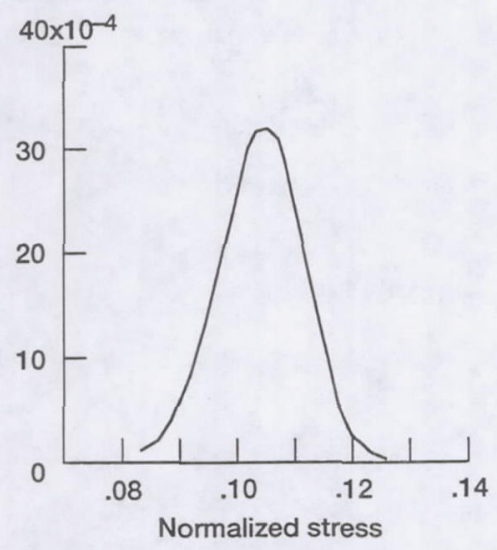

(c) Shear.

Figure 10.-Uncertainties - scatter range of normalized stresses in $-45^{\circ}$ ply (normalized by mean longitudinal stress).

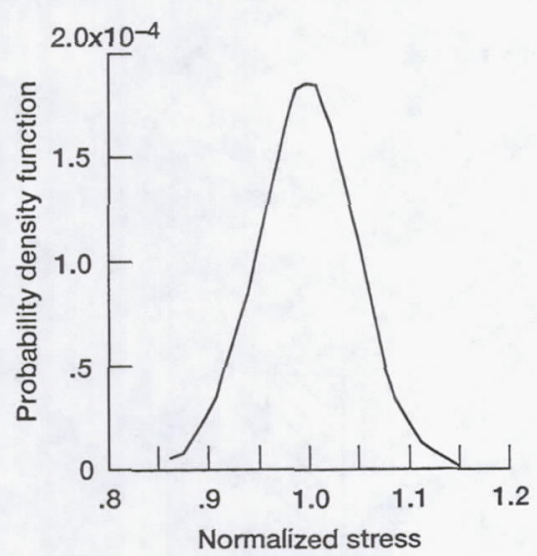

(a) Longitudinal.

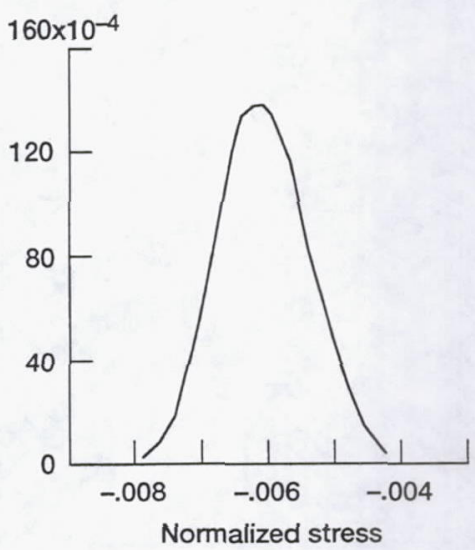

(b) Transverse.

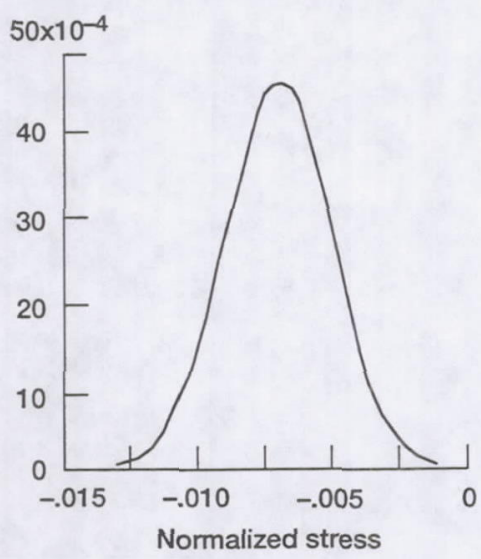

(c) Shear.

Figure 11.-Uncertainties - scatter range of normalized stresses in $0^{\circ}$ ply (normalized by mean longitudinal stress). 


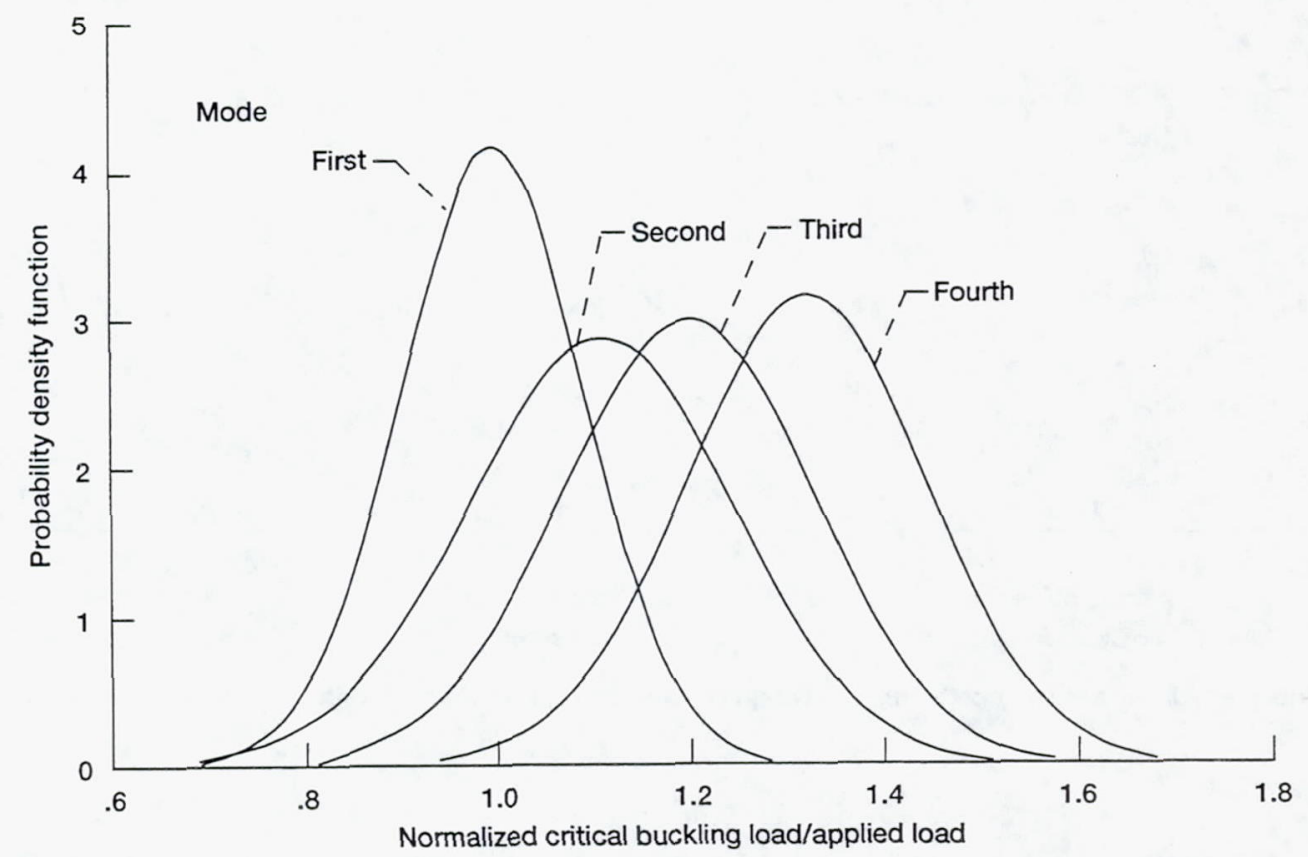

Figure 12.-Uncertainties - scatter range of buckling load (normalized by mean value of first mode).

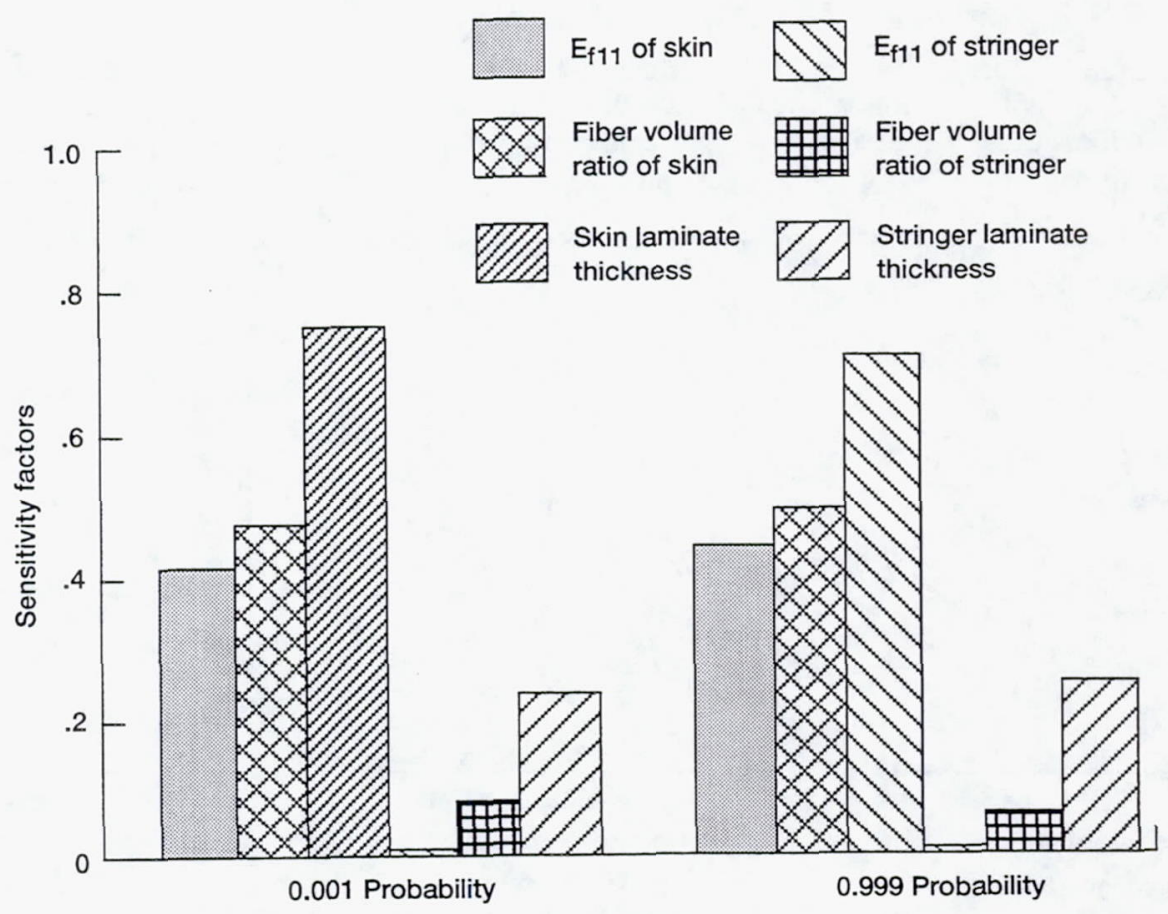

Figure 13.-Sensitivities of probabilistic of first buckling mode to significant uncertain variables. 


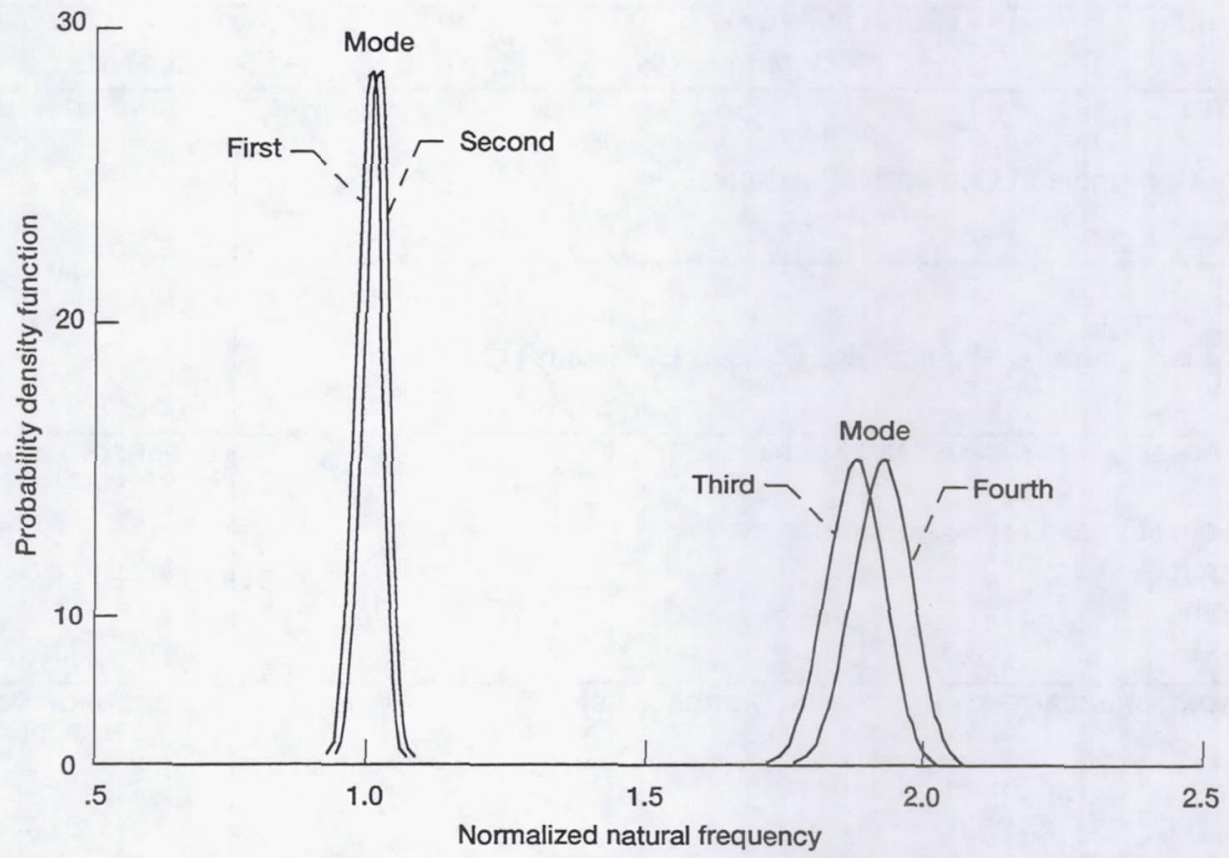

Figure 14.-Uncertainties - scatter range of natural frequencies (normalized by mean value of first mode).

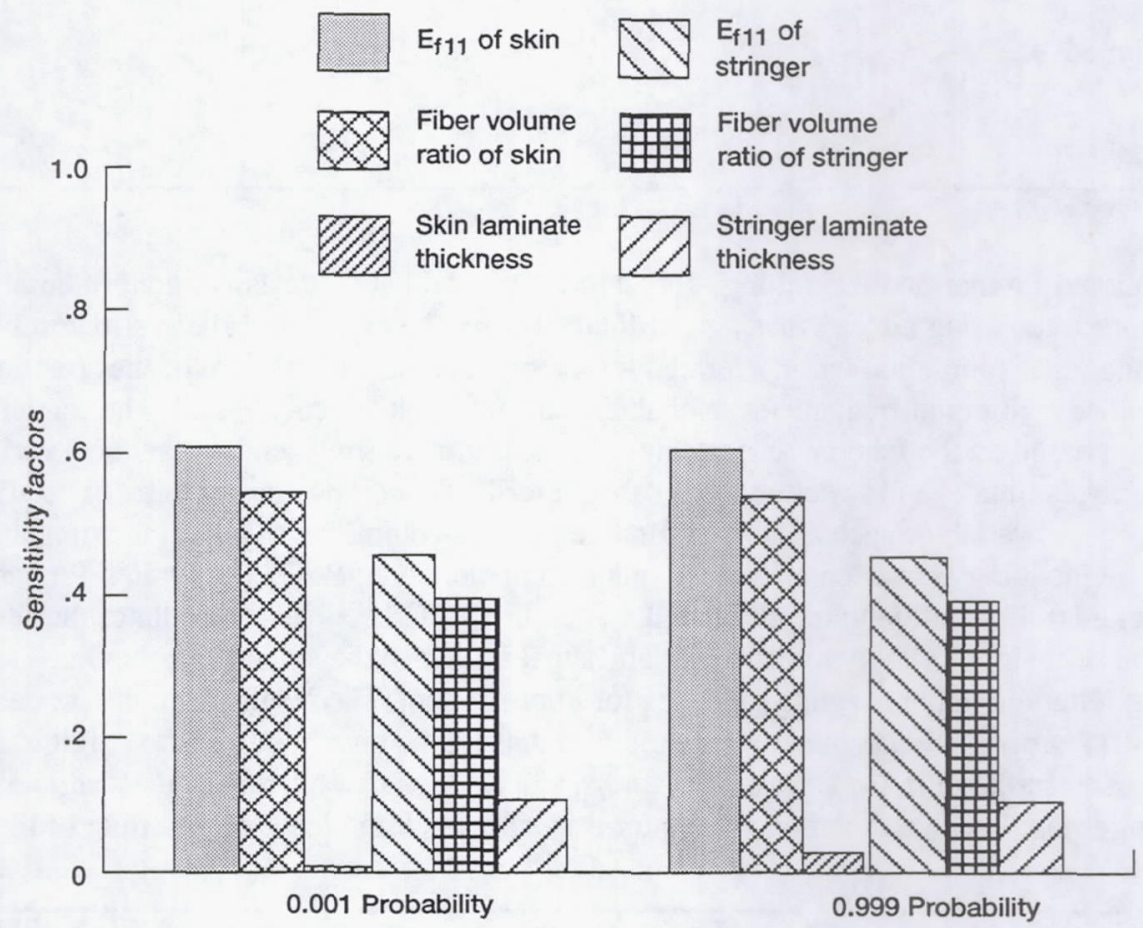

Figure 15.-Sensitivies of probabilistic of first natural frequency to significant uncertain variables. 


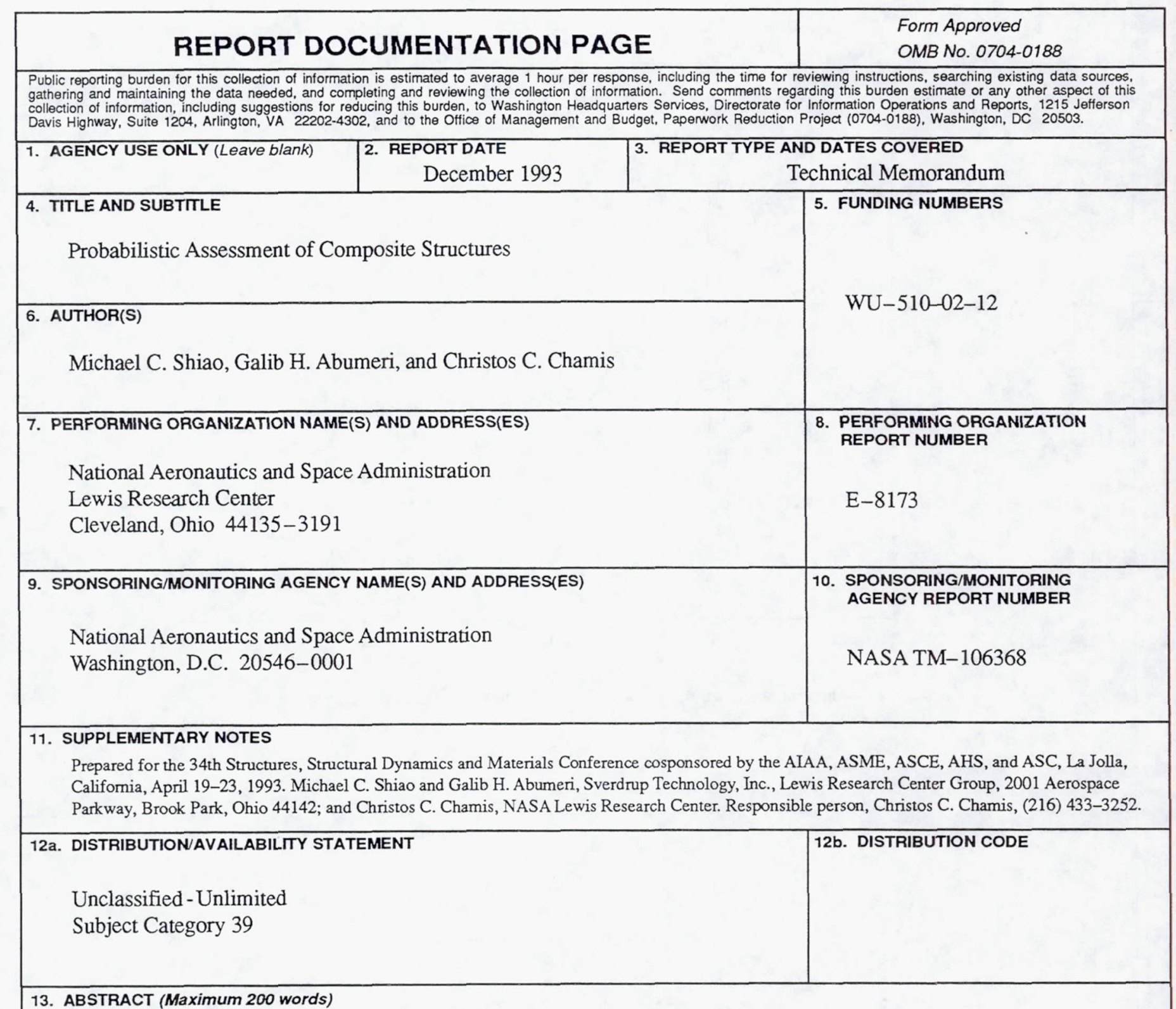

13. ABSTRACT (Maximum 200 words)

A general computational simulation methodology for an integrated probabilistic assessment of composite structures is discussed and demonstrated using aircraft fuselage (stiffened composite cylindrical shell) structures with rectangular cutouts. The computational simulation was performed for the probabilistic assessment of the structural behavior including buckling loads, vibration frequencies, global displacements, and local stresses. The scatter in the structural response is simulated based on the inherent uncertainties in the primitive (independent random) variables at the fibermatrix constituent, ply, laminate, and structural scales that describe the composite structures. The effect of uncertainties due to fabrication process variables such as fiber volume ratio, void volume ratio, ply orientation, and ply thickness is also included. The methodology has been embedded in the computer code IPACS (Integrated Probabilistic Assessment of Composite Structures). In addition to the simulated scatter, the IPACS code also calculates the sensitivity of the composite structural behavior to all the primitive variables that influence the structural behavior. This information is useful for assessing reliability and providing guidance for improvement. The results from the probabilistic assessment for the composite structure with rectangular cutouts indicate that (1) the uncertainty in the longitudinal ply stress is mainly caused by the uncertainty in the laminate thickness, and (2) the large overlap of the scatter in the first four buckling loads implies that the buckling mode shape for a specific buckling load can be either of the four modes.

\begin{tabular}{|c|c|c|}
\hline \multicolumn{3}{|c|}{$\begin{array}{l}\text { 14. SUBJECT TERMS } \\
\text { Composite; Probabilistic; Reliability; Fiber; Matrix; Ply; Laminate; } \\
\text { Uncertainty; Cylindrical shell; Opening }\end{array}$} \\
\hline $\begin{array}{l}\text { 17. SECURITY CLASSIFICATION } \\
\text { OF REPORT } \\
\text { Unclassified }\end{array}$ & $\begin{array}{l}\text { 18. SECURITY CLASSIFICATION } \\
\text { OF THIS PAGE } \\
\text { Unclassified }\end{array}$ & $\begin{array}{l}\text { 19. SECURITY CLASSIFICATION } \\
\text { OF ABSTRACT } \\
\text { Unclassified }\end{array}$ \\
\hline
\end{tabular}

15. NUMBER OF PAGES 16

16. PRICE CODE $\mathrm{AO3}$

\section{LIMITATION OF ABSTRACT}

